\title{
DON DON DORONDONDON: O DESLIZAMENTO DO SIGNIFICANTE (*)
}

\section{Lenice Pimentel}

...a palavra tem os seus crespos e os seus avessos...

Maria L. Ramos

No diálogo profícuo que a literatura promove com a cultura, cada vez mais temos o prazer de encontrá-la como material pulsante para compreender a história humana em seus temas cotidianos, e Drummond, com sua obra, ocupa uma posição privilegiada para pensarmos nesse entrelaçamento. Com sua maneira peculiar de observar e escrever a realidade, o Poeta tem na palavra uma aliada prestimosa para exercer o processo de mediação cultural como compromisso ético da literatura. O texto de Drummond instiga o leitor de todas as épocas a buscar algum significado para o texto.

O que me instigou a trabalhar os significantes de uma perda, a partir do poema "Cantilena prévia", na perspectiva da mediação cultural, foi a noção de cantiga suave, e, ao mesmo tempo, narração fastidiosa, toada monótona que expressa a dor como resto/rastro de uma perda. No poema, a morte em suas metáforas está em consonância com a acepção de morte vigente no século XX, tida como vergonhosa e/ou fracasso. Dela é melhor que nada se revele. A morte limpa, sem sinais, é a mais adequada para os padrões culturais vigentes. Kovács (1992) retoma a discussão dessa temática na sociedade ocidental e reafirma que a morte está despojada de seu caráter de necessidade em termos de processo vital, bem como o nãolugar para o luto. A vivência da dor deve ser controlada. Mas como expressar a dor que insiste em aparecer? Ramos (2000) defende a tese de que

(*) Este texto já foi publicado na revista Antígona, n.5, out./2002.

1 ANDRADE, C. D. de. Poesia completa e prosa. Rio de Janeiro: Nova Aguilar S.A. 1977. A falta que ama, p.429. 
há sempre uma forma de permanência na morte, que pode dar-se na natureza ou no seio de uma determinada cultura, onde transita do ético ao estético e ao metafísico. Porém, de qualquer perspectiva que seja considerada, o homem encontra sempre uma maneira de apropriar-se dela, manipulando-a por meio de ritos, denegando-a, fantasmatizando-a, de modo a livrar-se da angústia que o desconhecido provoca, do medo do caos, em que as referências se perdem (p. 165).

A literatura, espaço da palavra, tem sido generosa ao acolher os vários discursos que envolvem a morte, e Drummond, em Cantilena prévia, desde seu primeiro verso usa sabiamente a linguagem como presença que tenta preencher o lugar de uma ausência e aí anuncia algo de impertinente. Algo da ordem da repetição... Don don don dorondondon se impõe. O que se passa nessa cantilena? Que tramas linguageiras são evocadas para tecer a perda? Não é a linguagem uma das formas de recuperar o perdido? Poeta que é, Drummond caçou a palavra que existe na palavra para tentar dizer o indizível presente na cantilena. E por que prévia? O que se antecipa ao desejo de preencher "A falta que ama"? Que significantes deslizam desse dorondondon para chegar ao rinfonfon com sua idéia de completude?

Ao intitular seu poema Cantilena prévia, o Poeta introduz o lamento da vida, a evocação triste do pai amado como lugar de perda. Este lamento é parte das atitudes e crenças aprendidas dentro da cultura. Segundo Morin (1970), a sociedade funciona apesar da morte, contra ela, mas só existe, enquanto organizada pela morte, com a morte e na morte: "Don don dorondondon / É o Castelo de Drummond /que vai à penhora. // Don don dorondondon / É a soberba de Drummond / que vai-se embora. // Don don dorondondon / É o prazo de Drummond / que termina agora". Nas metáforas "Castelo", "Soberba" e "Prazo" presenciamos a refutação da morte que ao longo do poema, metonimicamente, vai sendo domada através dos imbricamentos da linguagem, apaziguando a dor. O sujeito que sofre exige ser enunciado, 'fura' a censura e, através da metáfora e da metonímia, fala do que pede retorno para além do código cultural. A literatura é o lugar de onde o sujeito pode falar. Chulam (1981) diz: 
A estrutura da linguagem dá ao homem condição de conjugar presença e ausência (Fort! / Da!) num tempo de alternância próprio, tanto ao homem, quanto à linguagem. O sujeito ressurge dessa ausência primordial ao entrar na grande cadeia substitutiva onde o significante marcará e falará o lugar dessa ausência (p.21).

Na cantilena, o que o Poeta procura é o que falta, e o que falta é exatamente o significante que dê conta da morte.

Na poesia drummondiana, à maneira dos ritos, os significantes da perda insistem na permanência do som, do dom, do tom, dos fios metonímicos que se reconhecem como bons, expondo as mazelas de vida e morte próprias de uma cultura que tem história e sobre ela reflete: "viver é modular a morte"2. Vejamos o poema de Carlos Drummond de Andrade:

Don don dorondondon

É o Castelo de Drummond que vai à penhora.

Don don dorondondon

É a soberba de Drummond que vai-se embora.

Don don dorondondon

É o prazo de Drummond que termina agora.

É o prazo de Drummond que ainda não termina.

Din din Resta uma resina.

Din din Resta uma farinha de substantivo, infra-som de voz, na voz de Drummond?

2 Palavras do psicanalista Hélio Pellegrino. 
Don don don

O morto Drummond

sorri à lembrança

De estar morto (don)

alva não-consciência

(din) de maior ciência.

Dindon dorondin din

O que sabe agora

não o diz Drummond.

Sabe para si.

Sabe por si só.

Sabe só, sem som.

É de rinfonfon.
É sem cor nem tom.
É completo. É bom.

Nesse poema, o que se repete insistentemente é a perda do Pai ainda em luto. Como preencher um espaço que não está de todo vazio? um lugar onde o prazo ainda não terminou? onde ainda resta uma resina, uma farinha ou uma lembrança e, no entanto, ainda faltoso? Com a palavra, Drummond engendra a perda do objeto de amor e coloca-o na ordem cultural para amenizar o sofrimento daquilo que se "sabe só, sem som". O Poeta precisa de tempo para se acostumar com a ausência:

Por muito tempo achei que a ausência é falta

E lastimava, ignorante, a falta.

Hoje não a lastimo.

Não há falta sem ausência.

A ausência é um estar em mim.

E sinto-a branca, tão pegada, aconchegada em meus braços, que rio e danço e invento exclamações alegres, 
porque a ausência, essa ausência assimilada, ninguém a rouba mais de mim. ${ }^{3}$

O texto literário, assim, cumpre o papel de mediar os processos culturais, uma vez que o "artista equaciona o pessoal e $\mathrm{o}$ cultural, o singular e o universal, a poesia e o mito, ${ }^{4}$ ao lidar com o jogo de significantes que se desenrola no texto. Certamente, em Drummond, não é uma brincadeira inocente rimar os versos. Há, aí, sem dúvida, uma supradeterminação dos termos que compõem a linguagem poética que anuncia a hora do Castelo, da soberba ou do prazo de Drummond.

Se a cantilena anuncia previamente a morte do Drummondpai, ao mesmo tempo anuncia sua permanência. Dele resta algo de substantivo suportado pelas imagens metonímicas de resina, farinha, lembrança, pois apesar "de estar morto (don) / alva não-consciência/ [no](din) de maior ciência" ele se faz presente. A morte cantada, falta (pre)sentida, se enlaça à cultura que chora os seus mortos de uma maneira contida. Drummond, nos versos da "Cantilena prévia", traz a "química silábica" referenciada por Freud num processo de interação com o significante - Don don dorondondon ... Dindon dorondin din e apresenta o don (de estar morto) como reverso do din (de maior ciência), contextualizando o que fica encoberto no nível das motivações inconscientes. Nesse jogo de significantes as palavras mapeiam a cartografia da dor buscando suporte na ciência. O controle é dado pelas palavras. Ainda com inspiração em Drummond:

Qualquer tempo é tempo

A hora mesmo da morte

É hora de nascer.

Nenhum tempo é tempo

bastante para a ciência

de ver, rever

ANDRADE, C. D. de. Ausência.

RAMOS, Maria Luiza. 2000, p.68. 


\section{Tempo, contratempo \\ anulam-se mas o sonho \\ resta, de viver. ${ }^{5}$}

Vida e morte, tempo e contratempo, aspectos de uma mesma realidade, encontram sua atualidade no aproveitamento que Lacan faz da banda de Möebius como forma de refazer a relação significante/significado estudada por Saussure. Uma fita torcida que passa da face exterior para a interior sem quebra de continuidade ilustra essa realidade presente nos textos de Drummond: "O morto Drummond / sorri à lembrança"; "A hora mesmo da morte / é a hora de nascer". O Outro ${ }^{6}$ habita o eu e dele não tem como fugir. Resta a palavra que canta no poema o ritmo da perda.

$\mathrm{Na}$ linguagem poética desliza sempre um outro sentido que se instala na cadeia significante, à revelia do Autor, e foi a isso que Lacan (1981) chamou de point de capiton, ou seja, há algo na escrita, na palavra, que fica aprisionado à superfície, deixando entrever o que está submerso no texto, recuperando o contexto, atuando em sua cultura.

Quer se trate de um texto sagrado, de um romance, de um drama, de um monólogo ou de uma conversação qualquer, vocês me permitirão representar a função do significante por um artifício espacializante, do qual se deve exercer toda análise concreta do discurso, eu o chamarei um point de capiton. (p. 303) ${ }^{7}$

Para entender a mediação cultural que perpassa na poesia de Drummond, basta ler com olhos e ouvidos atentos os seus escritos e neles encontraremos as dores e os amores do ser humano atualizados na cadeia significante, num "efeito que é de poesia ou de criação" ao mesmo tempo. Dizendo sempre mais do que suporta dizer, o sujeito lírico, sem o perceber, exercita, na linguagem, o capitonê, pois, quanto maior a censura, mais próximo da superfície da palavra chega o

5 ANDRADE, C. D. de. A falta que ama.

6 Conceito lacaniano segundo o qual o sujeito recebe a mensagem. Apud. WIBER, Ken. O espectro da consciência. Trad. Octavio Mendes Cajado. São Paulo: Cultrix, 1990, p.52.

7 LACAN, J. Le seminaire. Livre III - Les psychoses. Paris: Seuil, 1981. p.303.

8 LACAN, J. Ecrits. Paris: Seuil, 1966. p.515. 
significante barrado que se "sabe só, sem som". Evitando falar da morte do pai, outras palavras são conclamadas para comparecer à cena, mas, perversas, revelam o sujeito que sofre a dor da perda e, como já encontramos em Platão, elas são o "phármakon"necessário para mediar o cotidiano. Tudo vai depender de como essa palavra será falada ou escrita.

O nome Drummond, mencionado sete vezes no poema, faz jogo sonoro com as badaladas do sino (don don dorondondon) e perpetua o sentido que insiste na cadeia significante em busca da significação impossível imposta pela morte. Morte que permanece na lembrança, no tempo, na ausência, testemunhando a sua inexorabilidade. No nome a cantilena se realiza. A repetição, direta (Don don dorondondon) ou invertida no nome de Drummond, canta o sem jeito desse lado da vida presentificada na angústia do Poeta.

$\mathrm{Na}$ singularidade do poema, Drummond dialoga com a tradição ocidental, ao fazer da morte do patriarca, quando o seu prazo finda, um fato literário. O "Castelo de Drummond / que vai à penhora" adquire ares da "bela morte" cantada pelos gregos, pois não é um Drummond envelhecido que se vai, mas um Castelo (com maiúscula) que vai à penhora ou a soberba que se retira imponente, ao expirar 0 prazo. O que do pai fica penhorado, senão as lembranças que se estendem nos versos do Drummond-filho uma vez que essa perda, no começo do poema, ainda não é aceita? Do Dom - poder, privilégio, prestígio - qualidades admiradas no Castelo de Drummond -, chegamos ao Din, o saber da ciência, tornando possível fundir os tempos: Dindon dorondin din. Estabelecendo uma nova ordem. - a morte é parte da vida. Apaziguado na dor, os sons se harmonizam e podemos ouvir:

Dindon dorondin din

O que sabe agora

não o diz Drummond

Sabe para si.

Sabe por si só.

Sabe só, sem som. 
É ainda a elaboração do luto que está se fazendo no interior do Poeta. O que é sabido ainda não pode ser expresso: "sabe só, sem som". É o sentir que se exprime e que invade a subjetividade com sua força, no momento em que a morte irrompe o real em sua finitude. Inevitável, a morte está presente no desenvolvimento humano. Está dentro (don); está fora (din). É no "Don don don / (que) o morto Drummond / sorri à lembrança", e não é o amor uma das faces da morte? Não é dela primo? ... "Amor é primo da morte, / e da morte vencedor, / por mais que o matem (e matam) / a cada instante de amor.",

Amando o que resta do Drummond-pai (uma resina ou uma farinha), o mistério da morte apresenta o mistério da vida e, no Castelo de Drummond, ainda resta um clã e "...Alguém deste clã é bobo de morrer? / A conversa o restaura e faz eterno"... ${ }^{10}$ E é com as palavras, no seu rinfonfon, no esfrega/esfrega, que o Poeta lida com a falta, com a perda, fazendo da poesia ciência poética, pois sabe que é preciso viver para poder dissipar as ilusórias certezas da vida e da morte; esta é apenas uma invariante essencial da experiência humana. A morte "é sem cor nem tom" e o poeta, sabedor das coisas, junta perda e luto no sem cor que é, a um só tempo, símbolo da tristeza (representado pela cor preta $=$ a sem cor) e símbolo de paz e serenidade interiores. Com esta síntese o Poeta finda o poema, completando o ciclo vida-morte: é completo. É bom. ... É de rinfonfon.

A literatura, enfim, evidencia a função de ler e de fazer ler o dado cultural e literário com saber e sabor, e a poesia, em particular, é "uma rica e extraordinária elaboração da linguagem, que, se deixa entrever o poeta, o faz pela recuperação do contexto que o constitui, e, sobretudo, pela maneira criativa com que ele reage a esse mesmo contexto, atuando em sua cultura, ou seja, constituindo-a por sua vez."

\footnotetext{
9 DRUMMOND, C. As sem razónes do amor.

10 DRUMMOND, C. Conversa.

1 RAMOS, M. L. Op. Cit. p.75.
} 


\section{REFERÊNCIAS BIBLIOGRÁFICAS}

ANDRADE, C. Drummond. Reunião: 10 livros de poesia. 6. ed. Rio de Janeiro: J.Olympio, 1974.

BRAYNER, Sônia (org.). Carlos Drummond de Andrade. 2. ed. Rio de Janeiro: Civilização Brasileira, 1978. (Fortuna Crítica).

CHULAM, Tânia M. Olivier. Escritos sobre os escritos de Lacanroteiro de leitura - vocabulário e temas. Vitória: Fundação Ceciliano Abel de Almeida, 1981.

KOVÁCS, Maria Júlia. Morte e desenvolvimento humano. São Paulo: Casa do Psicólogo, 1992.

LACAN, Jacques. Le seminaire. Livre III - Les psychoses. Paris: Seuil, 1981.

MORIN, E. O homem e a morte.Lisboa: Publicações Europa-América, 1970.

RAMOS, Maria Luiza. Interfaces: literatura, mitos, inconsciente, cognição. Belo Horizonte: Editora UFMG, 2000.

WIBER, Ken. O espectro da consciência. Trad. Octavio Mendes Cajado. São Paulo: Cultrix, 1990. 